\title{
OS SISTEMAS ATMOSFÉRICOS E OS EVENTOS CLIMÁTICOS EXTREMOS NA REGIÃO DE CAMPO MOURÃO - PR
}

\author{
BORSATO, Victor Assunção - victorb@fecilcam.br \\ Universidade Estadual do Paraná / UNESPAR
}

MASSOQUIM, Nair Glória - nmassoquim@gmail.com

Universidade Estadual do Paraná / UNESPAR

\begin{abstract}
RESUMO: A cidade de Campo Mourão localiza-se na borda sul da linha do Trópico de Capricórnio, por isso a dinâmica climática apresenta características que oscilam estacionalmente e interanualmente. Consequências da circulação geral e regional, também da dinâmica das massas de ares e da configuração do relevo regional. $\mathrm{Na}$ circulação geral, a Região Sul do Brasil apresenta escoamento oeste leste, por isso, a climatologia é influenciada pelas ciclogêneses, pelas frentes frias, pela massa Polar Atlântica, pela massa Tropical continental e também pelos subsistemas. Essa região é rota dos cavados transientes em níveis superiores que se deslocam do Pacífico e a influência da topografia reforçam as ciclogêneses. Nessa latitude, no oeste da região, os fluxos da Corrente de Baixo Nível, condicionado pela barreira orográfica imposta pela Cordilheira dos Andes que barra a circulação nesse nível, direciona o escoamento para o Sul do Brasil e contribuem no desencadeamento das ciclogêneses. A região é também palco dos ventos polares e/ou tropicais. Por isso, o Sul é habitualmente transcorrido pelos sistemas frontais e pelas massas de ares polar e tropical. $\mathrm{O}$ ar polar mais denso em contato com o ar tropical gera os sistemas frontais que culminam nos principais episódios de chuva no Sul. Para as estações intermediárias, outono e primavera, os contrastes térmicos e de pressão atmosférica se intensificam e geram episódios intensos de chuva, vento e às vezes granizo, consequência da evolução dos Complexos Convectivos de Mesoescala ou do desenvolvimento de supercélulas. O objetivo principal da pesquisa foi analisar, por meio da dinâmica das massas de ares, as condições sinóticas para os eventos intensos em Campo Mourão, identificando a sua gênese na escala sinótica e na regional. Também se verificou, para os eventos extremos a probabilidade da recorrência e do tempo de retorno para 5, 10 e 20 anos e para área de abrangência de $1 \mathrm{Km}^{2}$ e 10 $\mathrm{Km}^{2}$, considerando que Campo Mourão encontra-se em áreas de manifestação frequentes de eventos extremos.
\end{abstract}

PALAVRAS-CHAVE: Climatologia Geográfica; sistemas atmosféricos; supercélulas.

\section{ATMOSPHERIC SYSTEMS AND EXTREME CLIMATE EVENTS IN THE REGION OF CAMPO} MOURÃO - PR.

ABSTRACT: The city of Campo Mourão is located at the southern border of the Tropic of Capricorn, leading to climatic dynamics with characteristics that oscillate seasonally and interannually, as a consequence of general and regional circulation, the air masses dynamics and the configuration of the regional relief. In the general circulation, the Southern region of Brazil presents east-west flows, thus the climatology is influenced by the cyclogenesis, the cold fronts, the Atlantic Polar mass, the continental Tropical mass and also by the subsystems. This region is a route of higher level transient troughs moving from the Pacific and the topography reinforces the cyclogenesis. At this latitude, in the west of the region, the low-level Jets, conditioned by the orographic barrier imposed by the Andes Mountains that avoid circulation at that level, directs the flow to the South of Brazil, contributing to the triggering of the ciclogenesis. The region is also a stage for polar and / or tropical winds. Therefore, the South is usually impinged by the frontal systems and the polar and tropical air masses. The interaction between the polar and the tropical airs generate the frontal systems that culminate in the main rain episodes in the South. For the intermediate seasons, autumn and spring, the thermal and atmospheric pressure contrasts intensify, leading to heavy rain, wind and sometimes hail 
episodes, as a consequence of the evolution of Mesoscale Convective Complexes or the development of supercells. The main objective of this research was to analyze, exploiting the air masses dynamics, the synoptic conditions leading to intense events in Campo Mourão, identifying its genesis in the synoptic and regional scale. For the extreme events, the probability of recurrence and time of return for 5, 10 and 20 years was also estimated for a range of $1 \mathrm{Km}^{2}$ and $10 \mathrm{Km}^{2}$, considering that Campo Mourão is in frequent manifestation areas of extreme events.

KEYWORDS: geographical climatology; atmospheric systens, supercels

\section{INTRODUÇÃO}

Os eventos climáticos extremos são aqueles que extrapolam os eventos habituais e também causam danos ao meio ou com potencial para danos. Eles ocorrem de muitas formas, como enchentes, secas prolongadas, ondas de calor, tufões e tornados (MARENGO, 2015). Dessa forma, os eventos climáticos extremos também são relativos à região onde se manifestam. Para o Sul do Brasil, o El Niño pode causar anomalias, principalmente no aumento das chuvas, por isso pode ser considerado como causador de eventos climáticos extremos.

Em anos de El Niño, a primeira consequência no clima do Brasil é o aumento das chuvas para o Sul do Brasil que, dependendo da duração e da altura precipitada pode causar enchentes e também episódios de chuva, granizo e rajadas de ventos (BERLATO e FONTANA, 2003).

Por outro lado, há grandes diferenças entre os eventos e episódios climáticos extremos, enquanto o evento pode ser um período seco prolongado ou uma enchente, resultados de uma sucessão dos estados do tempo que extrapolam o momento, um episódio é efêmero, da gênese à dissipação, evolui em períodos de horas. Uma tempestade de chuva intensa com granizo e vento intenso é momentânea e os danos, mesmo sendo "grandes", ocorrem em uma área restrita.

As tempestades estão associadas a arranjos ou condições atmosféricas orquestradas entre os principais atributos do tempo meteorológico, tais como a temperatura, a umidade relativa, a pressão atmosférica e características da superfície, por isso não são representadas nas cartas sinóticas, mas podem ser previstos (MOSCATI e GAN, 2007).

O Sul do Brasil e países vizinhos reúnem algumas características específicas que são propícias ao desenvolvimento de episódios intensos. Dessa forma, a região Sul do Brasil "experimenta" com relativa frequência, episódios climáticos extremos. É raro um ano em que o estado do Paraná não seja assolado por tempestades de chuva, vento e granizo. A grande maioria desses episódios intensos ocorre na estação da primavera, os quais estão associados à dinâmica dos sistemas atmosféricos que para essa estação é climatologicamente de transição do inverno para o verão, temporada em que atuam sistemas de alta pressão em contrastes com os de baixa. As interações entre os quais propiciam o desencadeamento de chuvas intensas e acompanhadas de granizo e ventos, às vezes intensos. Os sistemas atmosféricos de alta pressão são mais frequentes na estação do inverno e os de baixa no verão (TUBELIS e NASCIMENTO, 1992; BORSATO e MENDONÇA, 2013). Os contrastes térmicos e de pressão, desencadeiam episódios intensos de chuva, granizo e ventos que quando não atingem áreas densamente ocupadas, são pouco divulgados 
A pesquisa analisou, por meio das cartas sinóticas da Marinha do Brasil e imagens de satélite do CPTEC-INPE, a evolução dos sistemas que atuaram nos eventos de tempestades no estado do Paraná, levantados somente por meio dos noticiários via internet. O recorte temporal foi para a série histórica de 2004 a 2015, considerando-se que para os episódios registrados anterior ao ano de 2004 não estão disponíveis via internet para alguns jornais.

É interessante ressaltar que na busca de reportagem específica sobre danos causados por chuva, vento e granizo, abriu dois enfoques; o primeiro para os episódios de chuva, ventos e granizo noticiados; o segundo para queda de torres de transmissão de energia elétrica por episódios climáticos.

Foram catalogados para os dois recortes, 20 notícias de vendavais com registros de granizo, destelhamentos de casas, danos à arborização e queda de torres de alta tensão para o Estado do Paraná.

Para a queda de torres, selecionaram-se noticiários somente a partir de 2008, dada às dificuldades de se encontrar registros com essas informações em noticiários anteriores a esse ano. Para Oliveira (2007), no período de 1996 a 2006 foram registrados a queda de 16 torres em sete eventos climáticos. Segundo o mesmo artigo, em 1999, as Torres receberam reforços em suas estruturas para suportar ventos máximos de projeto de $188,2 \mathrm{Km} / \mathrm{h}$, ou 50,56 $\mathrm{m} / \mathrm{s}$. (OLIVEIRA, 2007). Portanto, mesmo depois de 1999, as quedas continuaram ocorrendo.

Considerando-se que o Estado do Paraná seja palco de episódios climáticos com potencial para danos, buscaram-se por meio da mídia impressa, principalmente em recortes de noticiários, verificar a frequência dos episódios intensos para o Paraná e também suas gêneses, por meio da análise dos estados do tempo, ou seja, buscou-se na dinâmica dos sistemas atmosféricos as condições sinóticas que propiciaram os episódios climáticos intensos.

Os resultados mostraram que os ciclogêneses que evoluem no Sul do Brasil, principalmente nos meses da estação da primavera, uma porcentagem deles tiveram potencial para desencadear tempestades severas na região de Campo Mourão.

\section{MATERIAIS E MÉTODO}

Os estados do tempo para os episódios que causaram tombamento de torres ou chuva intensa com ventos e queda de granizo foram analisados na perspectiva da Climatologia Geográfica, de acordo com a metodologia de Pédelaborde (1970). Os sistemas atmosféricos foram quantificados a partir da leitura e interpretação das cartas sinóticas da Marinha do Brasil (MAR-MIL, 2016) e nas imagens de satélite no canal infravermelho do CPTEC-INPE (2017).

Os sistemas atmosféricos considerados foram aqueles que atuaram na região, ou seja: Sistema Frontal (SF), massa Tropical continental (mTc), massa Tropical atlântica (mTa), massa Polar atlântica ( $\mathrm{mPa})$, massa Equatorial continental (mEc) (VIANELLO 2000; VAREJÃO-SILVA, 2000; FERREIRA, 1989). Para o registro foram elaboradas tabelas em planilha do Excel para os meses classificados como extremamente úmidos. 
Para os eventos extremos foram considerados os recursos da estatística. O risco foi deduzido dos conceitos fundamentais da teoria das probabilidades (TUCCI, 1993 e 1995).

Risco:

$$
R=100 *\left[1-\left(1-\frac{1}{T}\right)^{n}\right]
$$

$T$ é o período de retorno (ou tempo de recorrência), em anos;

$n$ é o número de anos;

$R$ é o risco permissível.

A probabilidade de que uma precipitação extrema de certa intensidade seja igualada ou superada uma vez dentro de um ano é igual a 1

$$
P=\frac{1}{T}
$$

Para a probabilidade o tempo de retorno considerado foi para 5, 10 e 20 anos e para área de abrangência de $1 \mathrm{Km}^{2}$ e $10 \mathrm{~km}^{2}$.

\section{CONSIDERAÇÕES SOBRE A DINÂMICA CLIMÁTICA E/OU ATMOSFÉRICA}

O Sul do Brasil situa-se em uma faixa, cujo escoamento atmosférico é de Oeste/Leste, região onde diversos fenômenos meteorológicos têm suas gêneses ou se manifestam por meio dos seus estágios evolutivos, da gênese à dissipação. Sendo os principais, as Frontogêneses, as Linhas de Instabilidades e os Complexos Convectivos de Mesoescalas (CCM). Os mais comuns e frequentes para o Sul do Brasil são os sistemas frontais, desencadeados a partir das ciclogêneses (GAN e RAO, 1991). Considerando que elas, as frentes, iniciam-se ou são desencadeadas pela ruptura do equilíbrio que há entre áreas da atmosfera com intenso gradiente de temperatura e pressão, que, em alguns dias depois, como o deslocamento é de oeste para leste, a frente já encontra no interior do Atlântico Sul e na área frotogênica (interior do continente) o equilíbrio é reestabelecido ou a região é invadida pelo anticiclone Polar.

Esse processo/fenômeno extrapola o território brasileiro e se estende até a borda leste da Cordilheira dos Andes, às vezes, evoluiao extremo sul do Brasil. Nesse período, o sistema frontal perpassa diversos estágios em seu ciclo, manifestado em basicamente três estágios principais: gêneses, amadurecimento e dissipação. Vários outros fenômenos meteorológicos configuraram-se sobre essa região. Esses fenômenos desencadeiam-se a partir de um "coquetel" de elementos geográficos e atmosféricos que se interagem e geram as perturbações (chuva, granizo, descargas atmosféricas e ventos intensos).

Para a meteorologia, a região é palco da manifestação de fenômenos de escalas sinóticas e sub-sinóticas. Na escala sinótica, os melhores exemplos sãos os avanços das massas de ar Polar e a ampliação da massa de ar Tropical 
continental. Além dessas, há também os fenômenos de escalas sub-sinóticas, tais como as Correntes de Jatos de Baixo Nível, as quais se encarregam de arrastar para o Sul do Brasil e países vizinhos, umidade da região Amazônica. Também se somam aos Sistemas de Cavados que transpõe a Cordilheira dos Andes, nessa latitude, muitos desses contribuem na evolução dos ciclones extratropicais que avançam pelo Sul do Brasil (MARENGO et al, 2013; SELUCHI e LICHTENSTEIN, 1991)

Também, de igual importância e em alto nível da Troposfera e já na circulação geral, tem-se sobre essa região a Corrente de Jato Subtropical que ao transpor a Cordilheira dos Andes sofre deformações e isso intensifica a ondulação que por fim, contribuem para o desencadeamento, em nível de troposfera, os ciclogêneses ${ }^{1}$.

É importante destacar também que o Sul do Brasil é climatologicamente influenciado pelos fenômenos de escala global "El Niño e La Niña" que, de forma breve, e somente para mencionar a sua importância para a climatologia do Sul do Brasil, o El Niño influencia nas chuvas, provocando aumento das precipitações e consequentemente aumentam-se também os episódios extremos para a região (BERLATO e FONTANA, 2003). Igualmente, a La Niña, embora com efeitos contrários, nos anos em que ela se manifesta, registra-se diminuição nos episódios de chuva para o Sul do Brasil, logo o volume também é menor. Há anos de manifestação do fenômeno La Niña que se verificam a ocorrência de veranico com drásticas consequências para a produção agrícola (ASSIS, et. al, 2006).

As chuvas intensas, cujos episódios torrenciais são aqueles que, geralmente, são de curta duração e de elevado acumulado. A maioria dos episódios são acompanhados de intensas descargas atmosféricas, ventos e granizos. Esses episódios são consequência do desenvolvimento de nuvens do tipo cumulonimbus (supercélulas), as quais apresentam grande desenvolvimento vertical e no seu estágio pleno, as chuvas são intensas e acompanhadas de rajadas de ventos. Embora pouco estudado e divulgado, essa tipologia de nuvens, principalmente para essa região, Sul do Brasil é dinamizada por duas correntes de ar, uma de média altitude "Correntes de Jatos de Baixo Nível" (MARENDO e SOARES, 2002) e a outra, a Corrente de Jato Subtropical.

A primeira abastece a região de umidade, considerando que ela tem sua dinâmica circunstanciada pela barreira imposta pela Cordilheira do Andes aos ventos alísios que, avançam do Atlântico norte para o interior da Amazônia, ao deparar com a barreira montanhosa e em determinadas circunstâncias atmosféricas são canalizados para o sul. Por outro lado, a Corrente de Jato Subtropical, quando intensificado e posicionado sobre essa região, causa, em função de suas características, certa sucção do ar a baixo nível, intensificando as correntes verticais que se desenvolvem na formação das nuvens cumulonimbus e nimbostratus (BARBOZA e FEDOROVA, 1998).

Essa tipologia de nuvens, no seu estágio de amadurecimento, provoca rajadas de ventos, consequência de colunas de ventos verticais que se desencadeiam no seu interior. Essas correntes têm como movimento principal,

\footnotetext{
${ }^{1} \mathrm{O}$ processo de abaixamento da pressão atmosférica de superfície e consequente formação ciclônica é denominado ciclogênese (gênese de ciclone). Dependendo das condições atmosféricas este fenômeno pode contribuir para a ocorrência de chuvas intensas e friagem em algumas regiões (CARDOSO et al, 2008).
} 
correntes descentes e horizontais que podem tocar o solo e causar danos à vegetação e edificações, quando for o caso. A meteorologia denomina esse vento de Microbursts, segundo Neto (2012), apud Fugita (1985).

\begin{abstract}
Fujita subdividiu os escoamentos descendentes de um downburst em macroescoamentos (macrobursts) e microescoamentos (microbursts). Os macroescoamentos estendem-se por áreas superiores a $4 \mathrm{~km}$ de diâmetro (mesoescala) e seus ventos duram de 5 a 30 minutos podendo chegar a uma velocidade máxima de $216 \mathrm{~km} / \mathrm{h}$. . Os microescoamentos estendem-se por áreas inferiores a $4 \mathrm{~km}$ de diâmetro e seus ventos duram de 5 a 15 minutos podendo atingir uma velocidade máxima de $270 \mathrm{~km} / \mathrm{h}$ (FUJITA, 1985) (NETO, 2012, p.14-15).
\end{abstract}

Dessa forma, é de se esperar que para o Estado do Paraná seja bastante comum eventos ou episódios intensos de chuva com granizo e ventos. Esses eventos, como as condições geomorfológicas não apresentam uma configuração que propicia a canalização das correntes horizontais do ar, espera-se que esses eventos ocorram aleatoriamente no espaço territorial e que haja possibilidades de episódios intensos assolarem uma cidade.

Embora não seja possível prever a localização da provável ocorrência das tempestades, em dadas condições ou arranjos sinóticos, é provável que aconteça, e a meteorologia, por meio do Sistema Meteorológico do Paraná, ou do Instituto Nacional de Meteorologia, emite alertas de tempestades sempre que essas condições são previstas. Por essa razão e por meio da estatística é possível calcular a probabilidade da ocorrência de um evento extremo para uma cidade ou localidade.

\title{
EVENTOS EXTREMOS - ANÁLISES
}

Os eventos, nessa pesquisa, foram classificados pela magnitude dos danos, considerando-se que um episódio intenso em uma área desocupada ou de baixa densidade humana como as rurais, não geram interesse da mídia. Para cada evento noticiado foi investigado as condições sinóticas para o estado do Paraná a partir de $72 \mathrm{~h}$ antecedentes ao evento. Considerando-se que para a climatologia dos eventos intensos é importante verificar a gênese por meio do sistema ou subsistemas atmosféricos.

O recorte temporal, para essa análise foi de 2004 a 2014. Nesse período, 20 episódios ou tempestades foram noticiados para o Paraná, sendo que para o ano de 2005 não se encontrou registro, e para os anos 2009, 2011 e 2012 foram três episódios para cada.

Iniciaram-se análise a partir do ano de 2004, para esse ano, foi noticiado um evento intenso, registrado em 14 de setembro.

Para esse episódio, o principal jornal a noticiar foi o "Estadão" de 14 de setembro cuja manchete trouxe a seguinte notícia: 


\title{
"Frente fria provoca chuvas e granizo no Paraná":
}

\begin{abstract}
Curitiba, 14 - As chuvas que chegaram ao Paraná depois de quase dois meses de estiagem trouxeram granizo e ventos fortes. De acordo com a Defesa Civil, a região mais atingida foi a dos Campos Gerais, sobretudo os municípios de Ventania e Ponta Grossa. Em Ventania, 244 residências foram atingidas, enquanto em Ponta Grossa 110 casas sofreram prejuízos. A Defesa Civil distribuiu Iona para as famílias substituírem temporariamente as telhas danificadas. Em Curitiba e região metropolitana, a chuva também foi bastante forte desde a meianoite até por volta do meio-dia de hoje, com precipitação leve de granizo. A Companhia Paranaense de Energia (Copel) registrou problemas de falta de energia para 101 mil consumidores de toda a região, em alguns locais durando apenas alguns segundos. Em outros foi necessária a presença de funcionários da estatal para troca de equipamentos queimados. A empresa atendeu 289 ocorrências em 22 bairros de Curitiba, enquanto na região metropolitana foram mais 445 . O Sistema Meteorológico do Paraná (Simepar) prevê que a chuva diminua de intensidade já a partir desta quarta-feira, com tempo bom na quinta e na sexta-feira. Para o meteorologista Samuel Braun, as chuvas e granizo não são incomuns neste período do ano. "O anormal nesse inverno foi a seca", registrou (AGENCIA ESTADO, 2004, p.1).
\end{abstract}

As análises iniciaram-se no dia 11 de setembro, um sistema frontal deslocava-se sobre o Atlântico Sul, especificamente sobre o litoral do Paraná e a massa Polar atlântica avançava pelo litoral da Região Sul. Nesse dia, a pressão máxima no centro anticiclonal oscilava em 1040 Hectopascal (hPa) sobre o estuário Platino. Em Campo Mourão, a pressão lida na carta foi de $1018 \mathrm{hPa}$. Para o dia 12, verifica-se que um ramo da massa Polar direciona-se avançando pelo oeste da Região Sul e também para o Centro Oeste e países vizinhos. Para - Paraná, um cavado estendia-se de norte para Sul, por isso a pressão em Campo Mourão oscilou em 1019 hPa. Na mesma latitude de Campo Mourão e a $60^{\circ} \mathrm{W}$, a pressão era de $1032 \mathrm{hPa}$. Numa distância de $8^{\circ}$ de latitude $\left(52^{\circ} \mathrm{W}\right.$ $60^{\circ} \mathrm{W}$ ) um gradiente de $13 \mathrm{hPa}$.

Para o dia 13, o ramo da massa Polar que havia avançado pelo interior do continente perdeu intensidade. Por outro lado, a baixa pressão, consequência do cavado se intensificou. A pressão atmosférica em Campo Mourão oscilou em $1020 \mathrm{hPa}$. Essa configuração mostra que o ar polar que avançou pelo interior do continente iniciou o processo de escoamento para Leste. O cavado manteve-se atuante principalmente no leste da Região Sul.

Para o dia 14, no qual foi registrado a chuva e granizo no Paraná, as condições sinóticas haviam evoluído assim: A massa Polar que havia avançado pelo litoral, encontrava-se sobre o atlântico e sendo assimilada pela Alta Subtropical do Atlântico Sul. A Baixa do Chaco que, para os dias anteriores, não se manifestou dada às condições do avanço do ar Polar pelo interior, ressurge e se intensifica na região de origem (Grande Chaco). A pressão atmosférica, naquela região, oscilou em $1014 \mathrm{hPa}$. Para o Sul do Brasil, o cavado evoluiu para uma ciclogênese, cuja pressão oscilou em $1014 \mathrm{hPa}$. A chuva, o vento e o granizo foram consequências da evolução desse ciclone, cuja gênese foi sobre o 
estado do Paraná (Figura 1 "A" e "B"). A carta sinótica do dia 13 mostra o cavado sobre o Sul do Brasil (Figura 1 "A"), e a do dia 14 mostra o sistema frontal no estágio inicial do ciclogênese, também no Sul do Brasil (Figura 1 "B").

No dia 15, a baixa do Chaco deslocou-se, juntamente com o ramo da frente fria que eclode no centro de baixa pressão sobre o Atlântico, a qual, no dia 14 encontrava-se sobre o Uruguai, avançando rapidamente para o Atlântico. Nesse mesmo dia, o sistema frontal conectou-se ao ciclogênese que avançava para o interior do Atlântico. Na Carta Sinótica do dia 15/09/2004, 12 h TMG (Tempo Médio de Greenwich), verifica-se que a massa Polar avançava pelo interior sul do continente, com pressão atmosférica oscilando em $1028 \mathrm{hPa}$. Para o dia 16, todo o Sul foi tomado pelo anticiclone polar, cuja pressão atmosférica oscilou para Campo Mourão acima de $1020 \mathrm{hPa}$. Ainda no dia 16 (cartas das $12 \mathrm{~h}$ TMG) mostra que a baixa pressão do Chaco se reestabelece, cuja pressão no centro ciclonal foi de $1006 \mathrm{hPa}$.
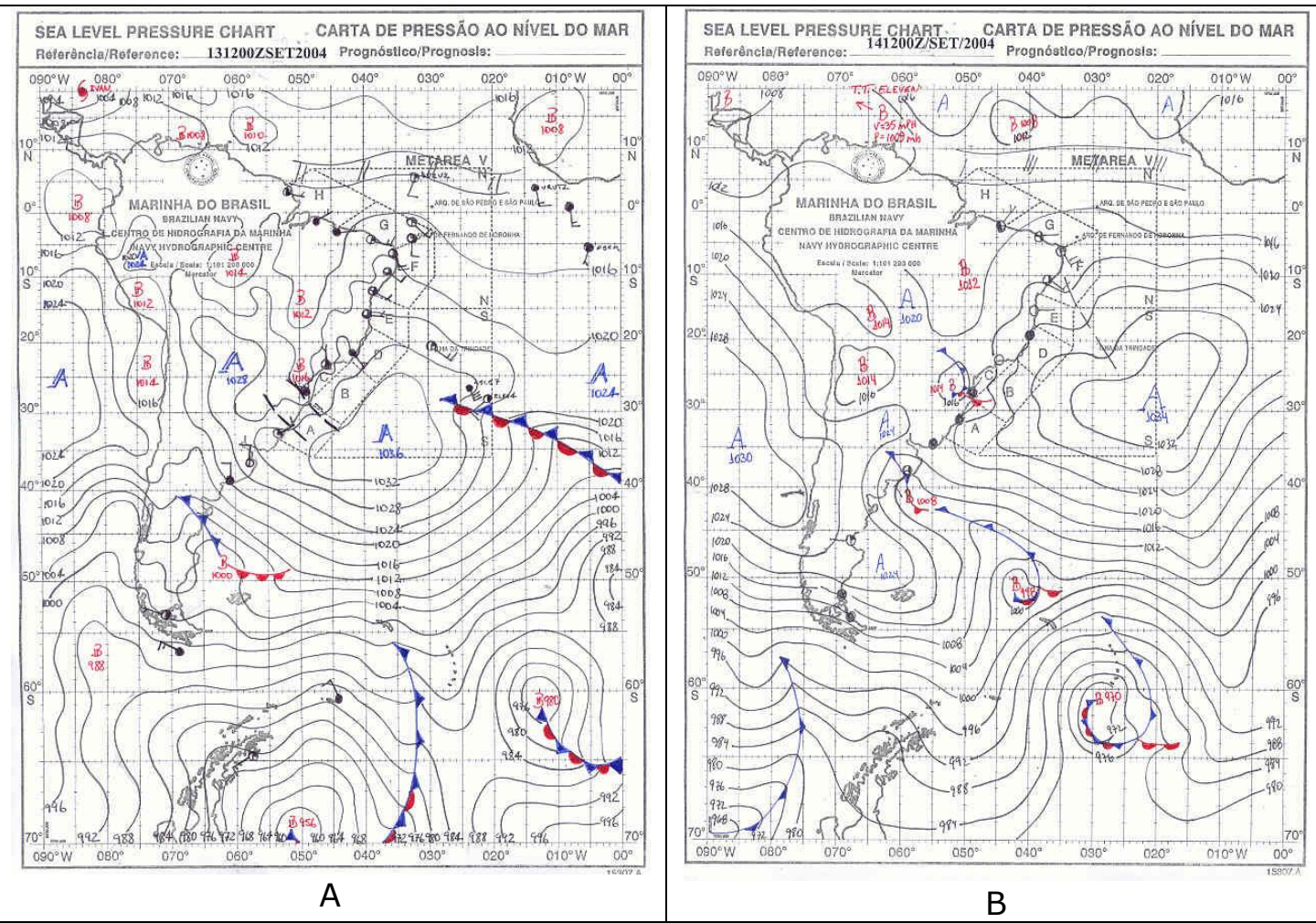

Figura 1 - Cartas sinóticas da Marinha do Brasil - A carta A é a do dia 13 de setembro de 2004 (12 h TMG) a simbologia mostra o cavado sobre o Sul do Brasil, em B, carta do dia 14, mostra que a baixa pressão (cavado) evoluiu para um ciclogênese.

Verifica-se que o episódio de vento e granizo foi consequência da evolução de um ciclogênese sobre o Paraná. A queda brusca na pressão gerou as perturbações atmosféricas que se desencadearam em chuva e granizo. É importante assinalar que a análise foi fundamentada para as condições verificadas para as cartas de superfície, e que certamente, a corrente de Jato de Baixo Nível e a Corrente de Jato Subtropical contribuíram para a intensificação desses episódios no Paraná. 
Dessa mesma forma, foram analisados os episódios que causaram queda de torres, o primeiro registro foi no dia 29 de outubro de 2008. As tempestades assolaram diversas cidades do estado do Paraná, conforme noticiou o Jornal Gazeta do Povo (YANO, 2008).

Torres de transmissão derrubadas pelo vento devem ser substituídas até sexta-feira. Uma equipe composta por 35 eletricistas, técnicos e engenheiros da empresa trabalha na montagem das novas peças. Fornecimento de energia está normal. Foi essa a manchete da Gazeta do Povo do dia 29/10/2008. (YANO, 2008).

Segundo a reportagem, diversas cidades do Paraná foram atingidas pelos temporais nesse dia; Foz do Iguaçu, Cascavel, Dois Vizinhos, Quedas do Iguaçu, Medianeira, Marquinho, Santa Maria do Oeste, Laranjeiras do Sul, Pitanga, Maringá, Loanda, Santa Cruz do Monte Castelo, Paranavaí, Sarandi, Marialva, Campo Mourão, Jandaia, Apucarana, Umuarama, Londrina, Bela Vista do Paraíso, Cornélio Procópio, Ibiporã, Guaraniaçu, Ouro Verde do Oeste, Rolândia, Itaguajé, Palmital, Inajá e Cafelândia.

Analisaram-se as cartas a partir do dia 26 e contatou-se que nesse dia havia um sistema frontal no Rio Grande do Sul e um centro de baixa pressão sobre o oeste e noroeste do Paraná, o qual estendia-se também para o Mato Grosso do Sul, Oeste de São Paulo e de Minas Gerais e uma massa Polar envelhecida sobre o Atlântico (Sudeste do Brasil). Esse sistema de baixa pressão deslocou-se para leste e desencadeou um ciclogênese. O qual, no dia 27 já se encontrava no Atlântico e o ramo frontal no Sudeste do Brasil. Verificou-se que a baixa pressão continental (baixa do Chaco), apresentava uma grande extensão norte/sul, prolongando-se deste $40^{\circ} \mathrm{S}$ até $10^{\circ} \mathrm{S}$ de latitude e abrangendo porções no oeste do território brasileiro e países vizinhos.

A análise da carta do dia 28 mostra que o ciclogênese se afastou da costa do Sudeste e uma "língua" de ar polar avançou pelo litoral da região Sul e partes do Sudeste. No interior do Brasil prevaleceram as baixas pressões, semelhante à configuração do dia 27. A pressão em Campo Mourão oscilou em $1012 \mathrm{hPa}$.

Para o dia 29, tempestuoso no estado do Paraná, verificam-se que as baixas pressões se ampliaram com deslocamento para leste, por isso a pressão em Campo Mourão oscilou em 1008 hPa (Figura 2 "A"). As cartas sinóticas mostram duas linhas de instabilidades no Sul do Brasil. Observou-se também, uma frente fria no litoral da Argentina e em $40^{\circ} \mathrm{S}$ e injeção de ar polar transpondo a Cordilheira do Andes ao sul de $40^{\circ} \mathrm{S}$.

Para compreender a gêneses das tempestades foi necessário analisar a carta do dia 30. O ar frio que avançava ao sul de $40^{\circ}$ configurou-se em um anticiclone e avançou pelo interior do continente (Figura 2 " $B$ "). A frente fria que se encontrava no litoral da Argentina avançou e conectou-se à baixa pressão que escoou para o Atlântico na configuração de um ciclogênese. Por isso, o ramo frontal transitou-se sobre o norte do Paraná e o núcleo de baixa deslocouse para o Atlântico. 

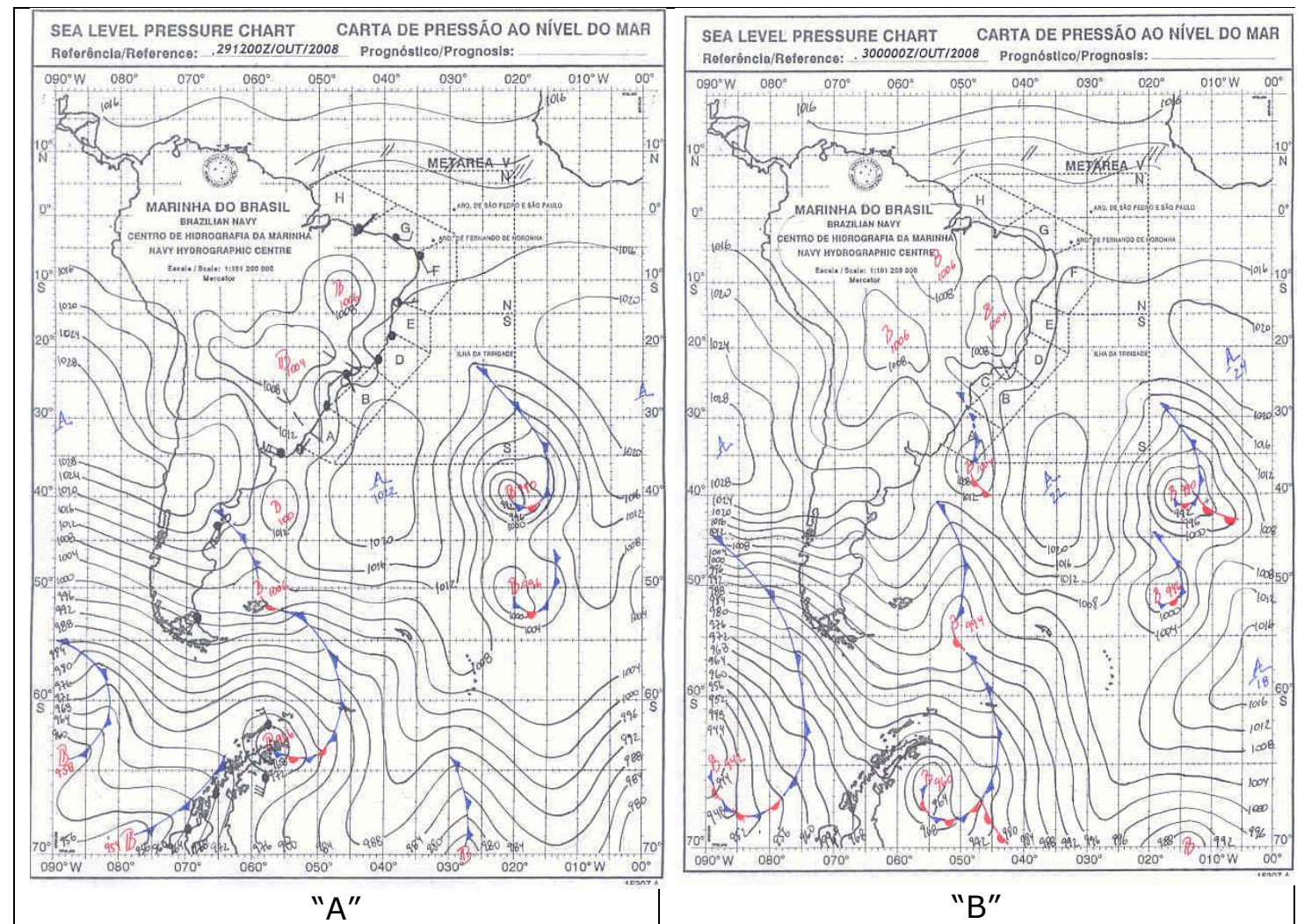

Figura 2 - Cartas sinóticas da Marinha do Brasil - A carta A é a do dia 29 de outubro de 2008 (12 h TMG) a simbologia mostra os cavados sobre o Sul do Brasil e as respectivas linhas de instabilidades, em B, carta do dia 30, mostra que a baixa pressão (cavado) evoluiu para um ciclogênese.

Esse rápido avanço de ar polar e a evolução da ciclogênese sobre o Paraná causaram o desenvolvimento de nebulosidade intensa com a presença de um Complexo Convectivo de Mesoescala que causou chuvas intensas com rajadas de ventos, as quais se generalizaram por uma vasta área, avançando do oeste ao extremo norte do Paraná. A Figura 3 é a imagem de satélite Goes-10 (canal infravermelho), ela mostra intensa nebulosidade sobre os estados do Rio Grande do Sul e Santa Catarina, que nesse momento, a densa nebulosidade iniciava a progressão pelo estado do Paraná. 


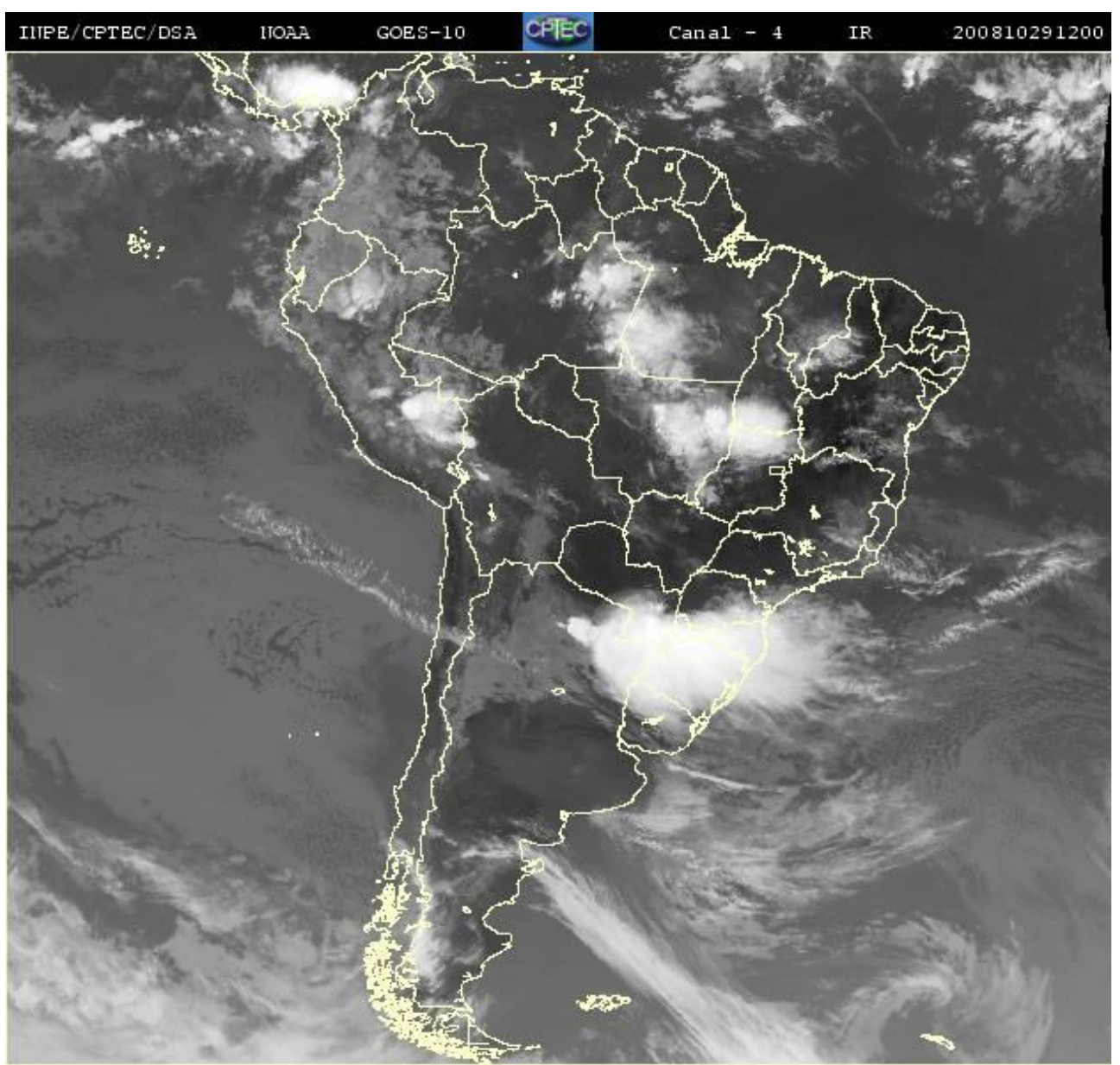

Figura 3 - Imagem de satélite no canal infravermelho, canal 4 (goes-10), disponibilizada pelo INPE-CPTE-DAS. A imagem mostra adensa nebulosidade sobre o Sul do Brasil no dia 20 de outubro de 2008 às 12 h TMG.

Para o dia 31, verifica-se que a massa Polar avançou até o Sul de São Paulo, por isso a pressão oscilou em 1016 hPa em Campo Mourão. O núcleo de baixa pressão do ciclone avançou para o interior do Atlântico Sul.

As análises das cartas mostram que o intenso gradiente de pressão entre o núcleo de baixa que se estabeleceu na região do Grande Chaco e o ar Polar que avançou pelo Sul do continente desencadearam a evolução do ciclogênese, cujo ramo frontal avançou de Sudoeste para Nordeste sobre o Estado do Paraná. As rajadas de ventos foram consequências do intenso gradiente de pressão e também do desenvolvimento de núcleos convectivos profundos (supercélulas) que acompanharam a linha frontal.

Todos os demais, 18 episódios, foram analisados a partir de 72 horas de antecedência, por uma questão de brevidade eles não serão apresentados, mas foram considerados para a finalização deste artigo.

Dos vinte episódios tempestuosos, 15 foram desencadeados a partir de ciclogêneses e cinco a partir do avanço de frentes frias clássicas ou a partir do desenvolvimento dos CCM. Para os episódios de frentes, cujo frontogênese 
ocorreu no extremo sul do continente, verificou-se que bolsões de ar polar avançavam pelo Atlântico e, às vezes, estendendo-se até o Pacífico, gerando um intenso gradiente de pressão e temperatura, principalmente para o oeste da região Sul, dada a proximidade com a região do Grande Chaco, local de depressão.

Para a queda de torres de transmissão de energia, o estado do Paraná, principalmente a região oeste, devido à Hidroelétrica de Itaipu há várias linhas e noticiam-se com frequência o tombamento das estruturas em consequência de episódios tempestuosos. Para a queda de Torres, foram 8 episódios, sendo que em dois deles também causaram danos às edificações.

As quedas de torres foram investigadas, considerando que em estudos publicados pela Furnas, Centrais Elétrica S.A (OLIVEIRA, 2007), mostram que as torres receberam reforços em suas estruturas para suportar vento máximo de projeto de $188,2 \mathrm{Km} / \mathrm{h}$, ou $50,56 \mathrm{~m} / \mathrm{s}$ ). Portanto, mesmo depois de 1999, quando as estruturas foram reforçadas, as quedas continuaram ocorrendo.

Para o período de 2008 a 2015, oito episódios de chuvas com ventos intensos derrubaram torres de transmissão de energia no Paraná. Desse total, cinco foram registradas na estação da primavera. Oliveira (2007) publicou um estudo, no qual abordou as quedas de torres para períodos anteriores aos dessa proposta, os resultados mostraram que houve inúmeros episódios que derrubaram estruturas (torres) de transmissão de energia no estado do Paraná.

A maior incidência das quedas de torres nesse sistema, totalizando dezoito ocorrências e quarente e cinco estruturas, iniciando em jun/82, com duas quedas não provocadas por ventos em sete/98 e jan/04, com sua última ocorrência em set/06, conforme detalha a tabela 2, abaixo.

Pelo histórico se observa que os períodos de maior incidência coincidentemente também são os meses de junho, setembro e outubro, e acrescentando-se o mês de novembro, e que os ciclos de reincidência se deram nos anos de 1982, 1990. 1994, 1997/98 e 2005/06, ou seja, uma média de intervalos entre ocorrências de cinco anos e meio.

Das ocorrências de queda por vento, $68 \%$ das torres caídas do tipo estaiada e os outros $32 \%$ de torres autoportante de quatro pernas, sendo que a proporção destas ao longo das LTs é de $70 \%$ de estaiadas.

O vento máximo de projeto dessas estruturas era de $150 \mathrm{Km} / \mathrm{h}$, ou seja, 41,67 m/s, tendo elevada em 199 para $182 \mathrm{Km} / \mathrm{h}$ $(50,56 \mathrm{~m} / \mathrm{s})$, devido à instalação de reforço estrutural na maior parte das estruturas do sistema (OLIVEIRA, 2007. P 3).

As análises das cartas sinóticas mostram que a maioria dos episódios tempestuosos evolui nos estágios iniciais de uma ciclogêneses. Para ampliar a discussão sobre as ciclogêneses no Sul do Brasil, vamo-nos remeter ao relevo e à circulação geral, para isso, devemos considerar que a Cordilheira dos Andes se constitui num importante obstáculo à circulação de baixo nível e também que o Sul do Brasil se encontra na zona limite das células de circulação geral, Célula 
de Ferrel e a Polar, faixa denominada de zona frontogenética. Também, deve-se considerar que, mais especificamente no final do inverno é o período em que o limite dessas duas células encontra-se mais ao norte, ou seja, sobre o Sul do Brasil. Da mesma forma que a Zona de Convergência Intertropical oscila para o norte ou para o sul da linha do Equador, os demais limites ou zonas entre as demais células de circulação geral também oscilam.

A zona limite das duas células de circulação geral e a elevação da Cordilheira andina oferece condições para o surgimento de uma célula depressionária temporária sobre a região do Grande Chaco. Para a meteorologia, na borda leste dos Andes há dois centros de baixa pressão, a Baixa do Chaco (BCH) e a Baixa do Noroeste Argentino (BNOA). Como estão próximos, são facilmente interpretadas como único centro depressionário (SELUCHI; SAULO, 2012).

O relevo depressionário do interior, assim como o escoamento da Corrente de Jato, em nível superior da troposfera contribui para que a região seja um local onde surgem ou intensificam fenômenos meteorológicos, que se ampliam e se manifestam também em território brasileiro, a partir do oeste.

Essa célula depressionária do interior do continente e nos limites das células da circulação geral desencadeia as ciclogêneses (Figura 4 " $A$ "). A imagem mostra o momento em que a onda de ar quente e de baixa pressão é invadida pelo ar mais frio. $\mathrm{O}$ ar frio de maior densidade força o ar quente a se elevar. Com a elevação, inicia-se um processo de convergência em baixos níveis, desencadeando a circulação ciclônica. Como o ar quente e frio não se misturam, desencadeia uma frontogênese (Figura 4 "B"), (BORSATO, 2015). Todo o escoamento do conjunto segue a circulação geral, e em um ou dois dias, o ciclone já se encontrará no Atlântico e depois de uma semana todo o ciclo se completa.

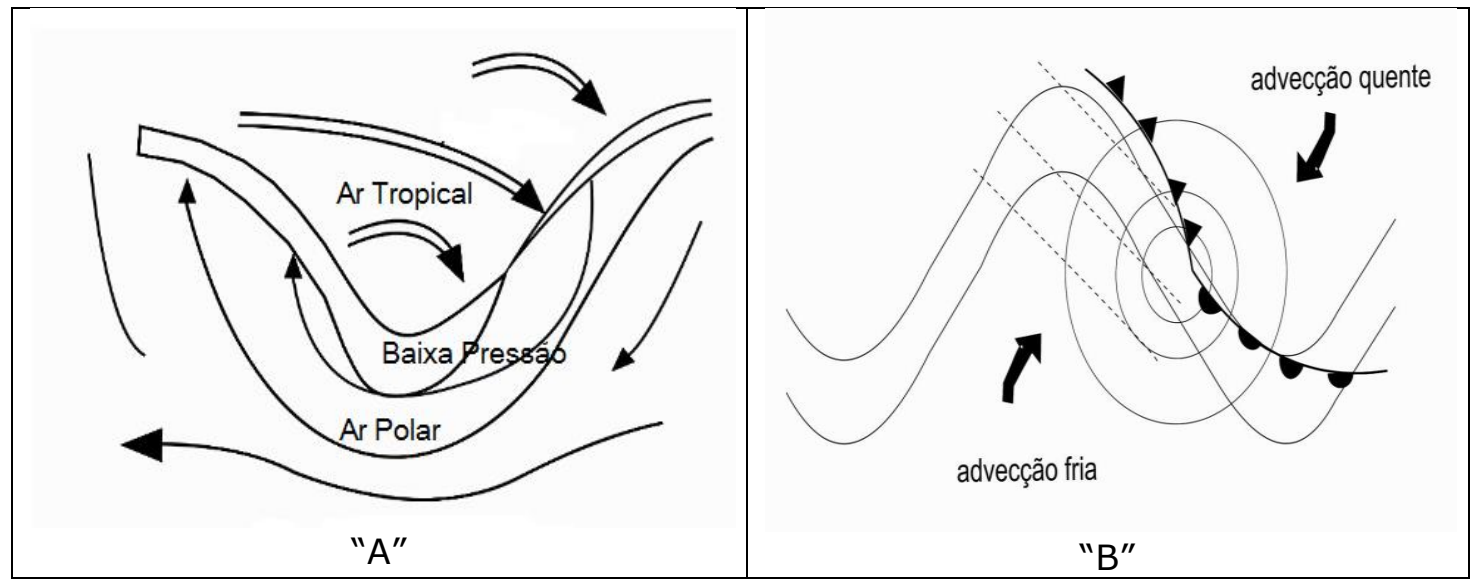

Figura 4 - Em " $A$ " Esquema simplificado do início de uma ciclogênese a partir da região do Grande Chaco. Fonte - Camargo e Frediani, 2004 (modificado). Em "B" Esquema da gênese de um sistema frontal clássico a partir de uma frontogênese em seu estágio intermediário - Fonte (BORSATO, 2016). 
Para a climatologia, a frontogênese corresponde ao "momento em que há sinoticamente a organização de um sistema frontal". Para a meteorologia, esse mesmo evento está associado aos distúrbios transientes que chegam ao continente sul-americano pela costa do Pacifico (ARRAUT, 2008). Para a mesma autora, "Os distúrbios sinóticos que produzem intensas frontogêneses nos subtrópicos/extras trópicos são os mesmos que dão origem às incursões de ar frio que produzem forte precipitação nos trópicos" (BORSATO, 2016, p. 53/54).

As Frontogêneses "ciclogêneses", para o Sul do Brasil, resultam das interações que se manifestam a partir da região do Grande Chaco, as quais resultam em mudanças de tempo para aquela região e também para áreas muita além, considerando que as "perturbações" se propagam ou se deslocam de oeste para leste, por essa razão, manifestam-se também em território brasileiro, principalmente no Rio Grande do Sul Santa Catarina e Paraná.

A literatura meteorológica mais afinada com os ciclones extratropicais e ciclogêneses contabilizam e quantificam a evolução deles para o Sul do continente (CPTEC-INPE, 2017). Nesse sentido, Gan (1992) contabilizou o número de ciclogêneses para a região de $90^{\circ} \mathrm{W}$ a $30^{\circ} \mathrm{W}-15^{\circ} \mathrm{S}$ a $50^{\circ} \mathrm{S}$ para $\mathrm{O}$ período de 1979 a 1988. Ao longo dos 10 anos, 1091 ciclogêneses evoluíram nessa região, sendo que o mês com mais frequência na série, foi maio, com 134 e o mês com menos, foi dezembro, com 71. A estação com mais frequência foi o inverno com 305 registros, seguido pelo outono com 302 e pela primavera com 268.

Verifica-se que o número de episódios de ciclogêneses para o Sul do Brasil é grande e que as eventuais tempestades registradas não é consequência do ciclone e sim do arranjo meteorológico que o dinamiza.

Em função disso, Aguiar (2006) estudou por meio de imagens de satélite os ciclogêneses, ciclones e suas influências sobre o estado do Rio Grande do Sul em episódios de El Niño e de La Niña forte e considerou:

A região de grande atividade ciclogenética, a qual se encontra aproximadamente sobre o Gran Chaco, Uruguai e sul do Brasil, possui características peculiares capazes de desencadear a formação ou intensificação de ciclones tempestuosamente catastróficos para a região sul do Brasil (AGUIAR, 2006, p. 12).

Para a série histórica, somente em 2005 não foram registradas tempestades com danos no estado do Paraná, para as fontes pesquisadas. Outra observação, com destaque, foi verificar que em 15 episódios estudados, as tempestades foram consequência do desenvolvimento de ciclogêneses sobre o Sul do Brasil, considerando o número de ciclogêneses apurados por Gan (1992). Calculou-se que $1,6 \%$ dos ciclogêneses que evoluem na região causaram tempestades no estado do Paraná.

Os episódios tempestuosos, considerando somente as cartas sinóticas de superfície, são consequências do aprofundamento da baixa pressão e seu deslocamento para leste e a injeção de ar polar pelo oeste do centro de baixa, o 
elevado gradiente de pressão desestabiliza a atmosfera. A região oeste do Sul do Brasil e países vizinhos, também, recebem umidade trazida pelas Correntes de Jato de Baixo Nível (MARENGO, 2002). São correntes de mesoescalas que atuam mais frequentemente nos meses de verão, elas transportam umidade da planície Amazônica para o Sul do Brasil e Argentina.

As correntes de Jato de Baixo Nível é a principal fonte de umidade do ar para a região do Grande Chaco e também para áreas a leste dessa planície, considerando que para a faixa latitudinal que se estende de $25^{\circ}$ a $35^{\circ} \mathrm{S}$, o escoamento atmosférico é de oeste para leste e o ar que transpõe os Andes sofre dissecação pela expansão adiabática.

A disponibilidade de umidade e calor também dinamiza os Complexos Convectivos de Mesoescalas. Mesmo sem ser objeto de pesquisa a quantificação dos CCM é importante destacar que para os 20 episódios tempestuosos estudados em pelo menos três, os CCM desencadearam o estado do tempo tempestuoso (REBOITA, 2004).

Os complexos convectivos de mesoescala foram definidos por Maddox em 1980, com base nas características físicas observadas em imagens de satélite no canal infravermelho. Segundo o autor, para um sistema ser classificado como complexo convectivo de mesoescala, algumas condições devem ser satisfeitas: a) uma região de nuvens com temperatura menor ou igual a $-32^{\circ} \mathrm{C}$ e ocupando uma área superior a $100.000 \mathrm{Km}^{2}$, b) o núcleo desse sistema teve possuir temperatura menor ou igual a $-52^{\circ} \mathrm{C}$ e ocupar uma área maior do que $\left.50.000 \mathrm{Km}^{2}, c\right)$ as condições a e b devem ser mantidas num período igual ou superior a 6 horas, d) o sistema deve ter uma excentricidade de 0,7 no momento de sua maior extensão e e) quando as características a e b não forem mais observadas, o sistema começa a dissipar-se (REBOITA, 2004, p. 30).

Para a América do Sul, os CCM manifestam-se na área entre as latitudes de $20^{\circ} \mathrm{S}$ a $40^{\circ} \mathrm{S}$. Segundo Velasco e Fritsch (1987), essas áreas são as de ocorrências e de seus processos dinâmicos e termodinâmicos. Eles são fortemente influenciados pela cadeia de montanhas dos Andes. Para Silveira e Teixeira (2011), os Complexos Convectivos de Mesoescalas estão associados ao Jato de Baixo Nível (JBN), que transportas umidade para a região gênese dos CCM.

Dessa maneira, Borsato e Massoquim (2016) estudaram a participação dos CCM nas chuvas da primavera de 2015 para o norte do Paraná e concluíram que nessa estação, $30,0 \%$ das chuvas registradas em Campo Mourão e em Maringá foram consequências da expansão dos CCM.

Diante dessas considerações, recorreram-se a estatística com o objetivo de verificar a probabilidade de um episódio de vento intenso com granizo atingir, especificamente, uma zona urbana que em área absoluta para as considerações tem apenas um quilômetro quadrado.

Foi considerada a área do município de Campo Mourão $(757,109$ km²). Mesmo sabendo que houve um evento extremo a cada ano, a probabilidade de 
ter atingido um bairro de $1 \mathrm{Km}^{2}$ é igual a $1 / 757=0,13 \%$. Na verdade, isso é a possibilidade do evento ocorrer em um ponto qualquer dentro de uma região de $1 \mathrm{Km}^{2}$.

Como a probabilidade de ocorrência na região é igual a 1 , então a probabilidade em um bairro de $1 \mathrm{~km}^{2}$ é $0,13 \%$, para um tempo de retorno de $1 / 0,13 \%=757$ anos.

Considerando tempo de retorno de 5, 10 e 20 anos:

$\mathrm{R}=1-(1-1 / \mathrm{T}) \mathrm{n}$ no qual $\mathrm{n}$ é o intervalo de tempo considerado, $\mathrm{T}$ é o período de retorno e $\mathrm{R}$ a probabilidade de ocorrência no intervalo $\mathrm{n}$.

Em 5 anos: 0,658\%; 10 anos: 1,31\%, e 20 anos: 2,61\%, 757 anos.

Considerando uma área de $10 \mathrm{Km}^{2}$. A probabilidade de o evento ocorrer em um ponto qualquer nessa área é de $10 / 757=1,32 \%$. Resultando em um tempo de retorno de 75,7 anos.

Assim, a probabilidade de recorrência em 5, 10 e 20 anos é respectivamente: $6,43 \%, 12,45 \%$ e $23,35 \%$.

A área total do bairro não entra no cálculo porque se calcula a probabilidade de o evento atingir um ponto em particular dentro da área considerada e não em sua totalidade. Por isso, considerou-se a área coberta pelo evento, $1 \mathrm{~km}^{2}$ e $10 \mathrm{~km}^{2}$.

\section{CONSIDERAÇÕES FINAIS}

Os resultados apontaram que foi na estação da primavera que ocorreram o maior número de episódios intensos. Nessa estação, as massas Polares ainda avançam intensas pelo interior do continente, por outro lado, o continente, em função do aumento do período de brilho solar, é mais aquecido, por isso o centro depressionário no Grande Chaco aprofunda-se. Esse contraste térmico e o escoamento atmosférico desencadeia os episódios, principalmente os ciclogêneses.

A intensidade dos episódios depende das interações das frentes com outros elementos dinâmicos que também atuam na região, as Correntes de Jato de Baixo Nível, as Correntes de Jato Subtropical, as células de baixa pressão na região do Grande Chaco e o escoamento dos sistemas de cavados, principalmente.

Os resultados mostram que $70,0 \%$ das tempestades ocorreram durante a evolução das ciclogêneses. Embora 0 número de ciclogêneses que se desencadeiam anualmente seja superior, a quantidade não foi contabilizada nessa pesquisa.

O tempo de retorno para $1 \mathrm{Km}^{2}$ foi de 5 anos: $0.658 \%$; 10 anos: $1.31 \%$, 20 anos: 2,61\%, 757 anos: 63,23\%. Para $10 \mathrm{~km}^{2}$, a probabilidade de o evento ocorrer em um ponto qualquer dentro de uma região é de $10 / 757=1,32 \%$. Resultando em um tempo de retorno de 75,7 anos.

Dessa forma, verifica-se que há probabilidade de um evento intenso assolar a cidade de Campo Mourão, considerando que eventos de chuva, granizo e vento são capazes de tombar torres de transmissão de energia, projetadas 
para resistir ventos de $188,2 \mathrm{Km} / \mathrm{h}$. Por isso, um episódio dessa magnitude nos bairros de construções antigas e com casas de madeira e cobertura de telhas de fibrocimento poderá causar danos severos. Deve-se considerar também que a grande maioria dos terrenos, além da casa há também plantas arbóreas mantidas pelos moradores, algumas frutíferas, outras de grande porte.

O grande número de quedas de torres de transmissão de energia, e também os episódios de chuva com granizo e rajadas de ventos, como já foram demostrados, ocorrem todos os anos e às vezes mais de uma vez. Também ficou evidente que são sistemas atmosféricos que desencadeiam as ondas tempestuosas, as quais avançam de oeste para leste, por conseguinte, em muitos episódios, são diversas cidades atingidas em um mesmo episódio.

\section{AGRADECIMENTOS}

A execução deste trabalho foi financiada pela Fundação Araucária de Apoio ao Desenvolvimento Científico e Tecnológico do Estado do Paraná. Chamada Pública 10/2013 - PRPPG/Unespar Apoio à Pesquisa Básica e Aplicada

\section{BIBLIOGRAFIA}

AGÊNCIA ESTADO, Frente fria provoca chuvas e granizo no Paraná. Estadão Portal do Estado de São Paulo. São Paulo, 14 de setembro 2004. Seção Notícia/negócio.

Disponível

em

<https://economia.estadao.com.br/noticias/negocios, frente-fria-provocachuvas-e-granizo-no-parana,20040914p712> Acesso em 28/06/2014.

AGUIAR, A. S., Utilização de imagens de satélites no estudo das ciclogêneses e ciclones e suas influencias sobre o estado do Rio Grande do Sul em Episódios de El nino e La nina forte, Dissertação de Mestrado - Universidade Federal do Rio Grande do Sul e Centro Estadual de pesquisas em Sensoriamento remoto e Meteorologia Programa de pós-graduação em sensoriamento remoto. Porto Alegre 2006.

ASSIS, S. V.; FERREIRA, A.T.; SILVA, M. V. Veranicos em Pelotas, RS: Climatologia e causas da ocorrência. In: Congresso Brasileiro de Meteorologia, Edição XIV. Florianópolis. Florianópolis, 2006.

BARBOZA, E. R., FEDOROVA, N. Corrente de Jato subtropical e complexo convectivo de mesoescala. Parte I: Situações sinóticas e correntes principais para a formação do complexo convectivo de mesoescala. In: Congresso Brasileiro de Meteorologia, 10, Brasília, 1998a. Anais... (CD-ROM).

BERLATO, M. A. \& FONTANA, D.C. El Niño e La Niña: Impactos no clima, na vegetação e na agricultura do Rio Grande do Sul; Aplicações de previsões climáticas na agricultura. Porto Alegre, Universidade Federal do Rio Grande do Sul, 2003. 110p.

BERLATO, M. A.; FONTANA, D. C. El Niño e La Niña: impactos no clima, na vegetação e na agricultura do Rio Grande do Sul; aplicações de previsões climáticas na agricultura. Porto Alegre: Editora UFRGS, 2003. 110 p.

BORSATO, V. A. e HEIRA, M. D.; Onda de calor em outubro de 2014 e os sistemas atmosféricos - Revista Equador (UFPI), Vol. 4, No 3, (2015). Edição 
Especial XVI Simpósio Brasileiro de Geografia Física Aplicada. Teresina- Piauí. Home: http://www.ojs.ufpi.br/index.php/equador> consultado em 23/02/2016.

BORSATO, V. A. A Dinâmica Climática do Brasil e massas de ares. Editora CRV. 1. ed. Curitiba, PR, 2016 182p.

BORSATO, V. A.; MASSOQUIM, N. G. A participação dos Complexos Convectivos de Mesoescala nas chuvas da primavera de 2015 no norte do Paraná. Anais do XII SBCGA - Simpósio Brasileiro de Climatologia Geográfica Aplicada Variabilidade e susceptibilidade climática: Implicações Ecossistêmicas e Sociais. Goiânia (GO)/UFG de 25 a 29 de outubro de 2016 Goiânia (GO)/UFG p 20-31 Disponível em <http://www.abclima.ggf.br/sbcg2016/anais/arquivos/eixo_1/trabalho\%20(3).p df>. Acesso em: 24 de fev. 2017.

BORSATO, V. da A.; MENDONÇA, F. de A. A dinâmica dos sistemas atmosféricos no verão 2012-2013 no Paraná e em Campo Mourão. Anais do Simpósio Nacional de Estudos Urbanos, 2., 2013, Campo Mourão. Anais eletrônicos... Campo Mourão: UNESPAR campus de Campo Mourão, 2013. Disponível em: <http://www.fecilcam.br/anais/ii_seurb/documentos/questao-ambientalurbana/borsato-victor-da-assuncao.pdf>. Acessado em: 13 jan. 2018

CARDOSO, C. de S; CRUZ, G. de S.; CALEARO, D. S.; Análise da Tromba d'Água de 02 de março de 2008 em Florianópolis/SC. 2008. In: XV Congresso Brasileiro de Meteorologia, 2008. São Paulo, 2008.

CPTEC/INPE - Instituto Nacional de Pesquisas Espaciais; De olho no tempo Meteorologia - Boletim técnico e previsão de tempo para os próximos dias Cptec/Inpe. Avenida dos Astronautas, 1.758 - Jd. Granja - CEP 12227-010, São José dos Campos. Disponível em <http://www.deolhonotempo.com.br/index.php> Acesso em: 28 de nov. 2017.

GAN, M. A.; Ciclogêneses e ciclones sobre a América do Sul. 1992. 221 f. Tese (Doutorado em Meteorologia) - Instituto Nacional de Pesquisas Espaciais, São José dos Campos, São Paulo, 1992.

GAN, M. A.; Ciclogêneses e ciclones sobre a América do Sul. 1992. 195p. (INPE 5400-TDI/479). Tese (Doutorado em Meteorologia) - Instituto Nacional de Pesquisas Espaciais, São José dos Campos, 1992.

MARENGO J.A.; e SOARES W. R. 2002. Episódios de Jatos de Baixos Níveis ao Leste dos Andes durante 13-19 de abril de 1999. Revista Brasileira de Meteorologia, 2002. 17(1): 35-52.

MARENGO JA, ALVES LM, SOARES WR, RODRIGUEZ DA, CAMARGO H, PAREDES $M$, and DIAZ PABLO A. Two contrasting seasonal extremes in tropical South America in 2012: Flood in Amazonia and drought in Northeast Brazil. Journal of Climate, 2013, 26:22, 9137-9154.

MARENGO, J. A.; Mudanças Climáticas e Eventos Extremos no Brasil. FBDS, 2009.

em: <http://www.fbds.org.br/cop15/FBDS_MudancasClimaticas.pdf>. Acesso em: 25 de jun. 2015.

MOSCATI, M. C. L.; GAN, M. A. Rainfall variability in the rainy season of semiarid zone of Northeast Brazil (NEB) and its relation to wind regime. International Journal of Climatology, n. 27, p. 493-512, 2007. 
NETO, W., T., D.; Estruturas de Torres sob ação de ventos originados de Downbursts. Dissertação de Mestrado - Programa de Pós-graduação em Engenharia Civil, COPPE, da Universidade Federal do Rio de Janeiro. Rio de Janeiro, 2012 (100 p).

OLIVEIRA, A. B.; Plano de atendimento a emergência com queda de torres em linhas de transmissão: medidas corretivas e preventivas; Furnas Centrais Elétrica S. A. XIX SNPTEE - Seminário Nacional de Produção e Transmissão de energia elétrica, GLT 09 de 14 a 17 de outubro de 2007, Rio de Janeiro, disponível em < http://www.cgti.org.br/publicacoes/wpcontent/uploads/2016/03/PLANO-DE-ATENDIMENTO-A-EMERGE\%CC\%82NCIASCOM-QUEDA-DE-TORRES-EM-LINHAS-DE-TRANSMISSA\%CC\%830-MEDIDASCORRETIVAS-E-PREVENTIVAS.pdf >. Acesso em: 26 de out. 2017.

REBOITA, M. S.; Elementos da Variabilidade Climática no Extremo Sul do Brasil, no Período de 1990 a 2001 - Rio Grande: FURG, 2004. Dissertação de Mestrado. - Fundação Universidade Federal do Rio Grande. Mestrado em Engenharia Oceânica. 2004. 211p.

SELUCHI, M. E. ; LICHTENSTEIN, E. R. Campos medios asociados a sistemas ciclónicos y anticiclónicos sobre la Argentina. Geoacta, Argentina, v. 19, n. 2, p. 125-136, 1992

SELUCHI, M. H. e SAULO, A. C.; Baixa do Noroeste Argentino e Baixa do Chaco: Características, diferenças e Semelhanças. Revista Brasileira de Meteorologia, v.27, n.1, $49-60,2012$

SILVEIRA, V. C.; TEIXEIRA, M. S.; Análise Sinótica de um Sistema Convectivo de Mesoescala formado sobre a região centro-oeste do Brasil In: Encontro Sul Brasileiro de Meteorologia, 4, 2011, Pelotas. Anais do IV Encontro Sul-Brasileiro de Meteorologia, 2011.

TUBELIS, A.; NASCIMENTO, F. J. L. Meteorologia descritiva: fundamentos e aplicações brasileiras. São Paulo: Nobel, 1992. 374 p.

VELASCO, I.; FRITSCH, J. M.; Mesoscale Convective Complexes in the Americas. J. Geophys. Res., v.92, n. D8, p.9591-9613, 1987.

YANO, C.; Torres de transmissão derrubadas pelo vento devem ser substituídas até sexta-feira. Gazeta do Povo, Curitiba, 29 de outubro, 2008, Seção Meteorologia. Disponível em < http://www.gazetadopovo.com.br/vida-ecidadania/torres-de-transmissao-derruba das-pelo-vento-devem-sersubstituidas-ate-sexta-feira-b9b|4i8hx8lcrs7wsegdr8mku>. Acesso em: $25 \mathrm{de}$ ago. 2015. 